\title{
Esporte como área de investigação e a ciência do esporte na Pós-graduação
}

http://dx.doi.org/10.11606/1807-55092017000nesp129

O Esporte constitui-se um dos principais fenômenos culturais do século XX, resultando em área de interesse de investigação desde então ${ }^{1}$. No que concerne à área profissionalizante, $\mathrm{TANI}^{2}$ propóe a caracterização do Esporte como uma área de pesquisa aplicada, e, por conseguinte, tendo como objetivo inerente a preocupação com a produção do conhecimento vinculado à capacidade de solucionar problemas práticos, através de suas subáreas ${ }^{2}$. O autor apresentava, à época, duas sub-áreas: treinamento esportivo e administração esportiva. Entretanto, nos dias atuais, é possível reconhecer que o desenvolvimento do Esporte como área profissionalizante e área de conhecimento, propiciou o amadurecimento e consolidação de outras áreas, ou como propôs TANI ${ }^{2}$, de outras subáreas.

No entanto, também é razoável se admitir que ainda estamos longe de um consenso para uma pergunta fundamental no que tange ao amadurecimento da área, especialmente quanto ao seu fortalecimento enquanto área científica $e$ de sua própria identidade. A pergunta norteadora para o programa de Pós-graduação da EEFE-USP, e seguramente, passível de ser discutida por outros programas e pela comunidade como um todo é: afinal, o que é Ciência do Esporte? Poderíamos adicionar questôes complementares, mas não menos importantes como: a quem interessa a Ciência do Esporte? Qual a relevância de se investigar o Esporte para o programa de Pós-graduação da EEFE-USP ou para outros programas? Por que fazê-lo e em que medida o esforço vale a pena, considerando o cenário da pesquisa atual, sobretudo quanto aos aspectos de financiamento e divulgação dos achados?

Essas perguntas, por vezes, parecem ter respostas óbvias; afinal, na área da Educação Física e Esporte, investigar o Esporte parece ser um caminho natural e razoável. Porém, ainda temos dificuldade em responder a primeira pergunta (o que é Ciência do Esporte?), e por consequência, a obviedade das respostas para as questôes "complementares" não é sustentada no mundo real.

\begin{tabular}{|c|c|}
\hline $\begin{array}{l}\text { Alexandre MOREIRA* } \\
\text { Emerson FRANCHINI* }\end{array}$ & $\begin{array}{l}\text { *Escola de Educação } \\
\text { Física e Esporte, } \\
\text { Universidade de São } \\
\text { Paulo, São Paulo, SP, } \\
\text { Brasil. }\end{array}$ \\
\hline
\end{tabular}

TANI $^{2-4}$ já ponderava acerca da importância e pertinência das consideraçóes sobre concepçóes de ciência, tipos de pesquisa e tipos de profissóes. De acordo com o autor, estas consideraçóes são "fundamentais para a discussão da identidade acadêmica e profissional de cada especialidade". TANI ${ }^{2-4}$ afirma que a definição da identidade de uma área de conhecimento é indispensável para que as atividades de pesquisa inerentes a uma área particular de conhecimento tenham coerência com essa definição. Ademais, também postula que os "conhecimentos produzidos tenham pertinência assegurada para poderem contribuir com o seu crescimento".

A questáo que se coloca entấo é se a pesquisa sobre Esporte no seio da nossa pós-graduação é claramente expressada em sua natureza. Temos clareza se esta é de natureza básica, aplicada ou tecnológica? Além disso, é esse o paradigma adotado no Esporte como área científica para as consideraçóes acerca de concepçóes de ciência e tipos de pesquisa? Os conhecimentos produzidos têm pertinência para contribuir com o desenvolvimento do Esporte, como área de conhecimento e, por conseguinte como especialidade? Estes conhecimentos têm sido apropriadamente transferidos para os profissionais desta área?

Há desenvolvimento e estímulo para isto na nossa pós-graduação, ou as áreas correlatas e disciplinas cientificas que em menor ou maior grau utilizam o esporte e ou amostras de esportistas como objetos de estudo são suficientes para o desenvolvimento da área e de uma teoria do Esporte? E se tal condição for assumida e considerando que essa abordagem se alinha com as exigências do programa (dos programas) e dos agentes externos de avaliação, no que se refere à produção do conhecimento e suas respectivas métricas, qual a razão da busca da identidade?

No programa de Pós-graduação da EEFE, por exemplo, diferentemente do apresentado por $\mathrm{TANI}^{2}$ em suas consideraçôes sobre as investigaçóes em Esporte, são contempladas duas grandes áreas de concentração, com suas respectivas 
linhas de pesquisa. Essas duas grandes áreas são denominadas "Estudos biodinâmicos da Educação Física e Esporte" e "Estudos socioculturais e comportamentais da Educação Física e Esporte". Essas duas grandes áreas por sua vez, envolvem "linhas de pesquisa" distintas. $\mathrm{Na}$ área de Estudos biodinâmicos da Educação Física e Esporte são contempladas as linhas de pesquisa da "Biomecânica do movimento humano", "Efeitos agudo e crônico do exercício no sistema cardiovascular", "Nutriçáo, atividade física e genética no esporte e na saúde, e "Desempenho esportivo". No que tange à área de Estudos socioculturais e comportamentais da Educação Física e Esporte, são apresentadas as linhas de pesquisa "Organização da resposta motora e aquisição de habilidades motoras", "Análise e diagnóstico do desenvolvimento motor", "Estudos socioculturais do movimento humano", "Aspectos Psicossociais do esporte", e "Gestão, Políticas, Marketing e Comunicação em Esporte e Educação Física”. Podemos assumir que o Esporte está intrínseca e implicitamente envolvido nas duas grandes áreas e em muitas das linhas do programa?

Para assegurar o crescimento da área e sua identidade no programa de pós-graduação da EEFE, e possivelmente em outros programas de nossa área, é imperativo a criação de mecanismos que efetivamente valorizem a pesquisa no esporte, e, sobretudo, a pesquisa do esporte e para o esporte. Fazse necessário que a comunidade científica envolvida, notadamente, dos pesquisadores vinculados aos programas de pós-graduação em Educação Física e Esporte e, portanto, também, das representaçóes em órgãos de apoio e fomento, sinalizem claramente para o caminho de interesse. Os programas têm interesse na pesquisa do e para o esporte? Os pesquisadores terão um reconhecimento no mesmo nível daqueles que produzem em áreas denominadas como "ciências-mãe"? Ou devemos admitir sem prejuízo de identidade que a área de estudos do Esporte é dependente de outras disciplinas científicas, e, portanto, como escreveu BRACHT ${ }^{5}$ (quando se referia à educação física), é colonizada epistemologicamente por outras disciplinas?

Todas essas questóes, por sua vez, poderáo ser mais eficazmente discutidas, a partir de um avanço no entendimento e reconhecimento de uma identidade e caracterizaçáo do Esporte como área científica e profissionalizante. Um aspecto central para uma melhor caracterização da área e, em consequência, para o fortalecimento de sua identidade e pertinência, é o entendimento acerca da preparação dos atletas e o corpo de conhecimento deste processo, assim como de sua finalidade e possibilidade de contribuição acadêmica e profissional.

O sistema de preparação do atleta, organizado estruturalmente pelos sistemas de treinamento, de competição, e de fatores complementares ${ }^{6}$ depende, dentre inúmeros aspectos, do sistema de conhecimento e formaçáo de profissionais e especialistas ${ }^{7}$. O sistema de conhecimento e formação de profissionais do Esporte e especialistas deve, portanto, estar fortemente associado à produçáo de conhecimento na dimensão da teoria do Esporte. Nesse sentido, mesmo considerando que o objeto da Educação Física - aqui compreendida como nomenclatura mais ampla para efeito de classificação da área em agências federais nacionais - se relaciona com o Esporte em certa medida, podendo-se assumir que têm a mesma base epistemológica, é também importante reconhecer que à medida que se desenvolvem apresentam diferenciação e, portanto, guardam características que denotam potenciais distintos para uma subsequente função.

MATVEEV $^{6}$ ressalta que para uma maior possibilidade de atender o problema do conhecimento da essência do Esporte e das tendências de sua funcionalidade e desenvolvimento, se necessita de um conhecimento científico especializado, orientado seletivamente para o problema em questáo; ou seja, para o avanço do conhecimento da essência do Esporte. MATVEeV $^{6}$ considera que o Esporte como uma área de conhecimento científico e sua consequente teoria (teoria do Esporte) deve estar destinado a refletir a essência do Esporte, de suas tendências gerais de funcionamento e desenvolvimento na sociedade. Ademais, sua questão central constitui a concepção sobre o conteúdo principal e forma de construção da preparação do atleta e, consequentemente, acerca de seus caminhos e condiçóes de aperfeiçoamento esportivo.

Considerando que a atuaçáo no Esporte segue o modelo das profissóes academicamente orientadas ${ }^{2}$, de alguma forma, a produção acadêmica deveria contribuir para a elevação da qualidade das açóes destes profissionais e, portanto, há a necessidade de desenvolvimento constante de pesquisas para que isso ocorra. Em nosso contexto, a atuação profissional está condicionada/limitada pelas leis vigentes que preveem a existência de conselhos e, portanto, os profissionais desta área (especialmente técnicos e preparadores físicos) estáo inseridos na área de Educação Física e sob regulação de seu 
conselho federal. Contudo, é preciso considerar que profissionais de outras áreas (p.ex., Nutriçāo, Fisioterapia, Medicina, Psicologia, Administração) também têm envolvimento com o Esporte e são regidos por seus respectivos conselhos. Portanto, há a necessidade de delimitação da área de intervençáo profissional em Esporte, bem como de suas características enquanto área de investigação.

Como área de intervençáo, este texto parte do pressuposto de que os profissionais de Esporte atuam com orientaçôes técnicas e táticas (i.e., técnico esportivo), preparação orgânica e funcional do atleta (i.e., preparador físico) e com a gestão e organização do esporte (i.e., gestor esportivo). Do ponto de vista de sua caracterização acadêmica, o conceito deve ser ampliado para o que é normalmente denominado Ciência do Esporte ("Sport Sciences" na literatura internacional). Assim, se assumirmos que as pesquisas no Esporte, para e do Esporte devem contribuir com uma área de conhecimento específica e, sobretudo, com o desenvolvimento da especialidade, é razoável admitirmos que as pesquisas do Esporte devem ser direcionadas para a intervenção, evidentemente, com certo grau de liberdade, mas contemplando a demanda pelo conhecimento nas áreas de intervenção, notadamente, no que diz respeito aos aspectos técnicos, táticos, psicofisiológicos e físicos. Adicionalmente, a investigação na área de gestão do esporte também deve ser desenvolvida, considerando sua importância para o processo de preparaçáa no Esporte e o desenvolvimento do Esporte como área de intervenção. Por outro lado, se a pesquisa nâo é direcionada à solução de um problema relacionado à intervençáo, poder-se-ia, sem prejuízo de identidade, ser conduzida em outra área de conhecimento e por pesquisadores de área correlatas e de diferentes disciplinas científicas.
A área de Ciência do Esporte, portanto, abrange diversas áreas do conhecimento que visam entender e otimizar o desempenho esportivo ${ }^{8}$. Uma das definiçóes propostas para a área, é que a mesma se constitui em um processo científico utilizado para orientar/guiar a prática esportiva, visando o alcance do desempenho máximo ${ }^{9-10}$. De acordo com esta definição, BısHop ${ }^{9}$ sugere que a investigação no âmbito esportivo deveria ter como finalidade principal a utilização do conhecimento científico (ou seja, da evidência disponível), no ambiente apropriado, para um determinado grupo de atletas e/ou um atleta específico, com o objetivo de otimizar o desempenho. Considerando esta definição, as pesquisas do e para o Esporte deveriam estar direcionadas para as áreas de intervençáo profissional. Deveriam ter como premissa, gerar conhecimento para o desenvolvimento da área científica, para o aprimoramento e aperfeiçoamento profissional, e qualificaçấo da prática de treinadores, técnicos, preparadores físicos, analistas de desempenho e profissionais envolvidos com estas funçóes. Estes, por sua vez, estabeleceriam interface com profissionais de área correlatas, os quais possuem suas próprias formaçóes, conselhos e associaçóes, como por exemplo, os nutricionistas, fisioterapeutas, psicólogos, médicos, jornalistas, ortodontistas, entre outros, que em maior um menor grau, têm participação efetiva no processo de preparação do atleta, como áreas de apoio.

Essa abordagem pode ser respaldada na necessidade do avanço do conhecimento decorrente de pesquisas inspiradas por consideraçóes de uso ${ }^{11}$ mas que ao mesmo tempo também buscam estender o conhecimento e entendimento geral. Nesse sentido, ao considerarmos a produção acadêmica de forma mais ampla, uma classificação que tem ganho inserção internacional é aquela proposta por STOKES ${ }^{11}$ (FIGURA 1).

Pesquisa inspirada por consideraçóes de uso?

\begin{tabular}{lll|l} 
& & \multicolumn{2}{c}{ Não } \\
\cline { 3 - 4 } $\begin{array}{ll}\text { Busca de entendimento } \\
\text { fundamental? }\end{array}$ & Sim & Pesquisa básica pura (Bohr). & $\begin{array}{l}\text { Pesquisa básica inspirada pelo uso } \\
\text { (Pasteur). }\end{array}$ \\
& Não & $\begin{array}{l}\text { Pesquisa direcionada a fenômenos } \\
\text { particulares. }\end{array}$ & Pesquisa aplicada (Edison). \\
\hline
\end{tabular}

FIGURA 1 - Modelo de quadrantes da pesquisa científica ${ }^{11}$. 
O quadrante superior (canto esquerdo) inclui a pesquisa conduzida com o objetivo central da busca do conhecimento, sem direcionamento "a priori" ou pensamento dirigido à sua utilização prática. STOKES ${ }^{11}$ considera que esse quadrante poderia ser denominado por Quadrante de Bohr, fazendo referência aos trabalhos de Niels Bohr, na procura por um modelo atômico e sua consequente contribuição para a compreensão da estrutura dos átomos e física quântica. De acordo com STOKEs ${ }^{11}$, o quadrante direito inferior inclui a pesquisa aplicada (Quadrante de Edison), ou seja, aquela guiada por objetivos aplicados, sem, necessariamente, contemplar a busca do entendimento mais geral dos fenômenos. $\mathrm{O}$ Quadrante inferior à esquerda diz respeito às pesquisas direcionadas para "fenômenos particulares", portanto, aquelas que não apresentam objetivos explanatórios gerais e também não são desenvolvidas no sentido de contemplar qualquer utilização prática. Movidas, portanto, pela curiosidade do investigador acerca de fatos particulares ${ }^{11}$.

Segundo esse modelo, o quadrante mais desejado por pesquisadores seria o que tem sido denominado como "Quadrante de Pasteur", pois nele seriam produzidos estudos que contribuíram simultaneamente para o avanço do conhecimento e para aplicaçóes imediatas. Embora não seja fácil fazer a transposição do referido quadro para a área de Ciência do Esporte, uma tentativa foi feita na FIGURA 2.

Pesquisa inspirada por consideraçóes de uso?

\begin{tabular}{|c|c|c|c|}
\hline \multirow{3}{*}{$\begin{array}{l}\text { Busca de entendimento } \\
\text { fundamental? }\end{array}$} & & Não & Sim \\
\hline & Sim & $\begin{array}{l}\text { Pesquisa básica pura } \\
\text { (Não atende as características } \\
\text { da área). }\end{array}$ & $\begin{array}{l}\text { Pesquisa básica inspirada } \\
\text { em aplicação (A.V. Hill). }\end{array}$ \\
\hline & Não & $\begin{array}{l}\text { Pesquisa direcionada a fenômenos } \\
\text { particulares (ou para atender as } \\
\text { exigências burocráticas particulares). }\end{array}$ & Pesquisa aplicada (“swimming suit"). \\
\hline
\end{tabular}

FIGURA 2 - Adaptação dos quadrantes da pesquisa científica proposto por STOKES ${ }^{11}$ à área de Ciências do Esporte.

Com base nesta figura, as pesquisas conduzidas pelo ganhador do Nobel em Fisiologia ou Medicina de 1922 , Archibald Vivian Hill, sobre metabolismo do lactato e sobre o consumo máximo de oxigênio $\left(\mathrm{VO}_{2 \text { max }}\right)$ possibilitaram avanços tanto nos conceitos científicos da área de fisiologia do exercício quanto aplicaçóes imediatas para a prescrição do treinamento físico de atletas e estariam no "Quadrante de Pasteur" e, como em outras áreas, seriam o ideal também para qualquer pesquisador da área de Ciência do Esporte. As pesquisas de aplicação direta também deveriam ser enfatizadas para os que pertencem a essa área, tais como o desenvolvimento de técnicas, procedimentos ou produtos que contribuiriam diretamente para a melhora do desempenho de atletas. A pesquisa básica pura não atende às características da área de Ciência do Esporte e, embora sejam importantes para o avanço científico, não deveriam ser conduzidas ou priorizadas em unidades de pesquisa com foco em Ciência do Esporte. Por fim, vale ressaltar que a pesquisa no quadrante inferior esquerdo, implica na motivaçáo do pesquisador de investigar algo "particular" e assim, com relativa limitação para o avanço no conhecimento científico ou solução de problema aplicado de maior abrangência, o que parece ser um caminho não recomendável.

Recentemente, dois exemplos vindos da GráBretanha reforçaram a importância da produção acadêmica para a otimização do desempenho esportivo: 1) ReEs et al. ${ }^{12}$ descreveram detalhadamente o "Great British Medalists Project", que culminou com a conquista, pelo país, do segundo lugar no quadro de medalhas dos Jogos Olímpicos do Rio de Janeiro 2016; deixando clara a relevância da orientação acadêmica para a tomada de decisão no esporte de alto rendimento; 2) a "start-up" Wizdom.ai reportou logo após os Jogos do Rio de Janeiro o posicionamento de diferentes países quanto à produção acadêmica relacionada às modalidades esportivas disputadas nos Jogos do Rio de Janeiro 2016, criando um quadro de medalhas da ciência aplicada ao esporte. Ao analisarmos os dados divulgados pela "start up" (https://wizdom.ai/dashboards/olympics-research) e os dados oficiais do quadro de medalhas dos Jogos 
do Rio de Janeiro 2016 (https://www.rio2016.com/ quadro-de-medalhas-paises) e conduzirmos uma correlaçáo de Spearman entre os posicionamentos em cada quadro, encontramos $\mathrm{r}=0,84$ para $\mathrm{o}$ total de medalhas e 0,70 para as medalhas de ouro. Ainda que a correlaçáo não implique causa e efeito, fica nítido o relacionamento entre países que mais produzem pesquisa e que mais conquistam medalhas. Ainda que essa relação possa ser mediada por outros fatores (p.ex. Índice de Desenvolvimento Humano [IDH], Produto Interno Bruto [PIB], etc.), é importante considerar a possibilidade de forte influência do desenvolvimento científico sobre o desempenho esportivo, o que justificaria maior investimento e incentivo às pesquisas nesta área, se a política esportiva nacional objetivar melhoria do desempenho brasileiro em competiçóes internacionais.

Por outro lado, é preciso considerar que a maior parte da produçáo acadêmica brasileira em Ciência do Esporte advém dos programas de pósgraduação das universidades nacionais - sobretudo as de natureza pública dos sistemas estaduais e federal. A avaliação destes programas é feita pela Coordenação de Aperfeiçoamento de Pessoal de Nível Superior (CAPES) e tem forte influência da produção científica em periódicos indexados. Contudo, uma rápida observaçáo dos periódicos da classe superior (A1) do sistema Qualis para a área de Educação Física (na qual a Ciência do Esporte estaria contemplada), resulta na obtenção de poucos periódicos em que a temática Esporte aparece de forma pronunciada. Adicionalmente, é comum que os periódicos em "Sport Sciences"13 apresentem valores de fator de impacto inferiores ao de outras áreas (p.ex., "Physiology", "Psychology", "Genetics"), nas quais pesquisadores de programas na área de Educação Física (o equivalente nacional ao "Sport Sciences" internacional) também têm seus trabalhos publicados. Como a decisão de direcionamento de verbas para pesquisa, obtenção de bolsas, etc, segue esse modelo de produção acadêmica, é provável que os pesquisadores na área de "Sport Sciences", que atuem exclusivamente com pesquisas nesta temática, tenham maior dificuldade em atingir os valores de fator de impacto preconizados.
O fator de impacto de periódicos é um dos indicadores adotados por "rankings" internacionais e por agências de fomento para compor os critérios de avaliação de periódicos e programas de pósgraduaçáo. O fator de impacto leva em consideração o número de artigos produzidos em dois anos consecutivos e a citação destes trabalhos em um terceiro ano ${ }^{13}$. Por exemplo, um periódico que tenha publicado 100 trabalhos em 2014 e 105 trabalhos em 2015, com citações destes trabalhos 110 e 115 vezes em 2016, respectivamente, teria um fator de impacto de 1,098. Como o fator de impacto é característico de cada área, as comparaçóes entre áreas não são recomendáveis ${ }^{13}$.

Para além da análise individual do pesquisador, acerca de sua produção, publicação de artigos, e o fator de impacto dos periódicos nos quais estes artigos foram publicados, é importante destacar que no tocante à avaliação dos programas de pósgraduação nacionais, a produção em periódicos internacionais tem sido um dos aspectos valorizados. Internacionalmente, a área de pesquisa em Esporte é denominada "Sport Sciences". A FIGURA 3 apresenta a produção brasileira e a produção da Universidade de São Paulob (Painel A) e a produçáo da USP em relação ao total nacional (Painel B), para o período de 1977 a 2016 (acesso conduzido em 05/04/2017). Considerando o painel A desta figura, é possível observar que até meados da década de 1990 a produção nacional em "Sport Sciences" era basicamente dependente da produção da Universidade de São Paulo. Contudo, com o crescimento dos programas de pós-graduaçáo na área de Educação Físicac ${ }^{c}$, sobretudo a partir da segunda metade dos anos 2000, é possível verificar crescimento bastante acentuado da produção vinculada à "Sport Sciences" no contexto nacional em ritmo mais acentuado do que aquele apresentado pela produção vinculada à Universidade de São Paulo. O painel B indica claramente essa tendência, pois até meados dos anos 2000 existe grande oscilaçáo na relação representada neste painel, com estabilização em torno de $25 \%$ a $30 \%$ da produção da Universidade de São Paulo em relação ao total nacional. Considerando a expansão do número de programas, é expressiva a participaçáo da Universidade de São Paulo no contexto nacional. 


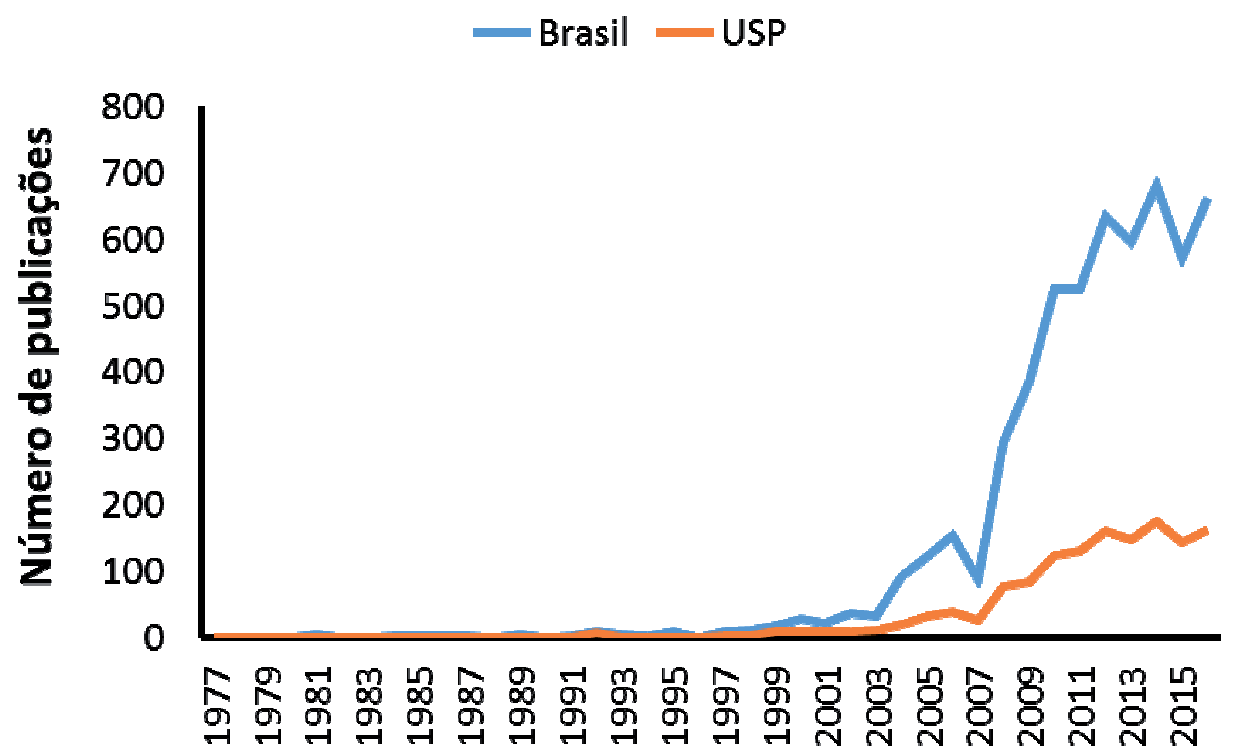

\section{Ano}

Painel A



Painel B

FIGURA 3 - Produção brasileira e da Universidade de São Paulo, de 1977 a 2016, em "Sport Sciences” indexada na base Web of Science, em valores absolutos (painel A) e produção da Universidade de São Paulo em percentual do total nacional (Painel B).

Os dados apresentados na FIGURA 4 representam o total de citaçôes na área de "Sport Sciences" da produção nacional e da Universidade de São Paulo (painel A) e a relação entre número de citações dos trabalhos conduzidos por pesquisadores vinculados à Universidade de São Paulo em relação ao total nacional (Painel B). O painel A indica que até a primeira metade da década de 2000 , as citaçóes de 
trabalhos brasileiros decorriam de citaçóes a trabalhos produzidos por pesquisadores da Universidade de São Paulo. Claramente, houve aumento substancial do número de citaçóes a partir da segunda metade da década de 2000, com as citações a trabalhos da Universidade de São Paulo representando cerca de $35 \%$ do total de citaçôes a trabalhos nacionais, reforçando mais uma vez a importância desta universidade no contexto da internacionalização do conhecimento científico nacional na área de "Sport Sciences". Chama atenção também o fato de que o número de citação por item produzido é de 5,30 para a produção nacional e de 7,77 para a produção vinculada à Universidade de São Paulo.

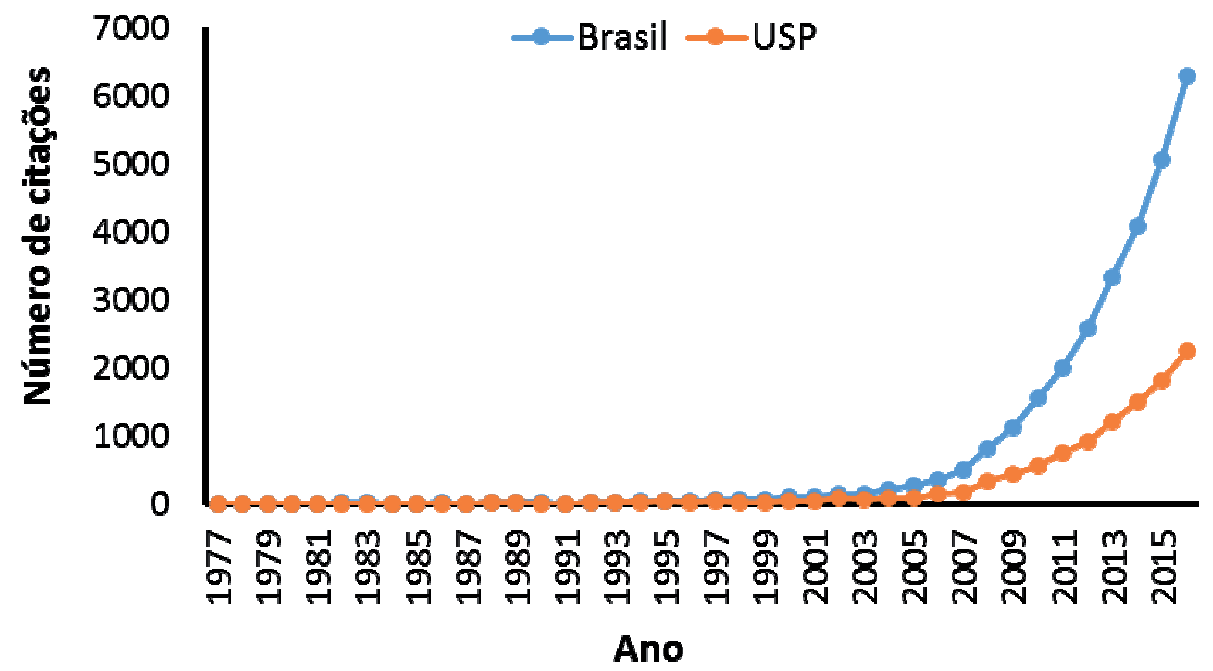

Painel A

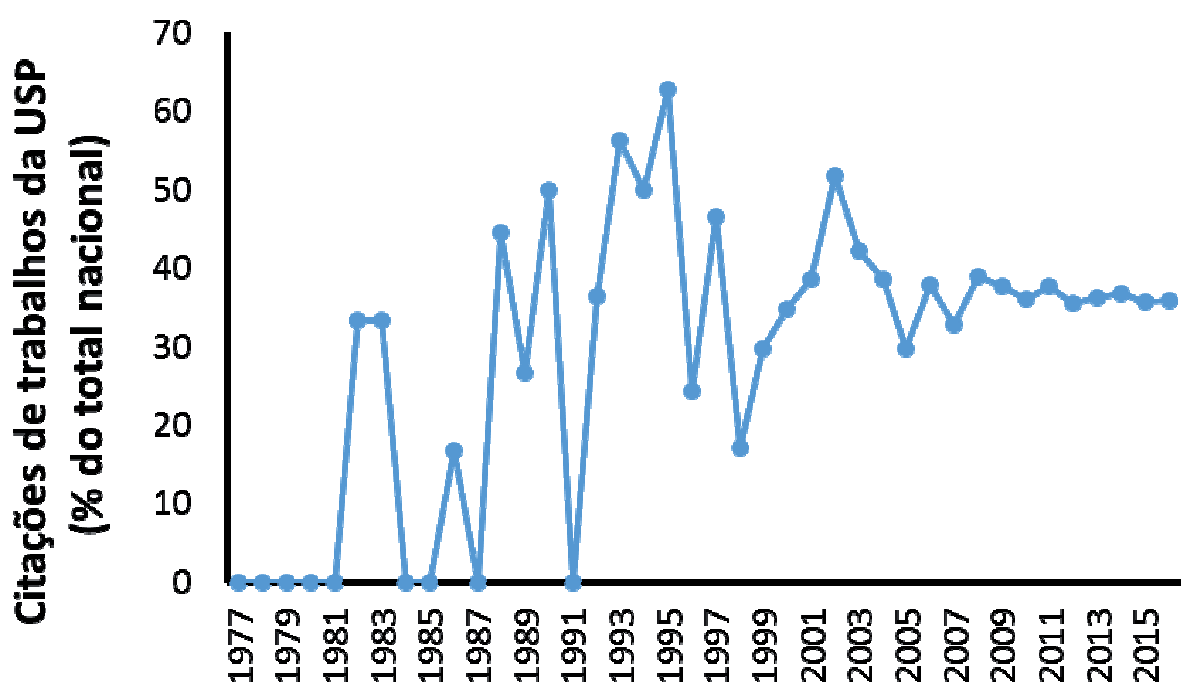

Ano

\section{Painel B}

FIGURA 4 - Número de citações de trabalhos brasileiros e da Universidade de São Paulo, de 1977 a 2016, em "Sport Sciences" indexada na base Web of Science, em valores absolutos (painel A) e citações de autores vinculados à Universidade de São Paulo em percentual do total nacional (Painel B). 
Recentemente, ranqueamento internacional (Shanghai Ranking) apontou a Escola de Educação Física e Esporte da Universidade de Sáo Paulo como a 22a na área de "Sport Sciences", o que certamente demonstra a inserçáo desta Escola no sistema de produção acadêmica internacional nesta área. Contudo, para o desenvolvimento da área em nível nacional, é importante o levantamento das principais instituiçôes com foco nesta área, bem como de seus pesquisadores com maior produção e contribuição específica para as áreas de intervenção no Esporte, para que incentivos via agências de fomento/sistema federativo-confederativo/ ministérios possam ser delineados e alocados para a manutenção de pesquisa de boa qualidade nesta área. Em levantamento recente $(22 / 11 / 2016)$, no indexador Web of Science, observamos que as universidades nacionais com maior produção em Sport Sciences foram: USP, UFRGS, UNIFESP, UFRJ, UNICAMP, UFMG, UEL, UFSCar, UFSC e UNESP. Vale ressaltar que a produção da USP era, naquele momento, responsável por $25,4 \%$ do total desta área em toda a sua história.

Todavia, apesar do destacado ranqueamento acima citado, do importante percentual de contribuição da USP para a produção em "Sport Sciences", e ainda, da elevada participação de universidades nacionais no contexto da disseminaçáo do conhecimento científico em "Sport Sciences", esses dados refletem a publicação

\section{Considerações finais}

O presente texto teve a intenção de contribuir com o avanço das discussóes acerca do Esporte como área científica e profissional. As questóes levantadas devem ser mais frequentemente debatidas e amadurecidas para que esse avanço seja de fato consolidado. A proposição de uma melhor caracterização da área é condição essencial para nortear a lógica dessas discussóes e apontar caminhos. Em editorial da RBEFE, já se registrava a preocupaçáo com os caminhos e direcionamentos da Ciência do Esporte e com a produção pertinente à área. Moreira ${ }^{14}$ indagava acerca do efeito dos grandes eventos esportivos no Brasil e a condução de pesquisa em Educação Física e Esporte. Notadamente, no que se refere ao Esporte, questóes foram levantadas e no presente texto, foram novamente exploradas e direcionadas à reflexão de trabalhos de pesquisadores de programas na área de Educação Física, como destacado anteriormente nesse texto, o "equivalente nacional ao Sport Sciences internacional". Ressalta-se ainda que essa publicaçáo deve ser analisada, considerando também a produção advinda de outras unidades da USP e outros programas de pós-graduaçáo das demais universidades nacionais com destaque na produção em "Sport Sciences". Assim, no que concerne ao desenvolvimento e fortalecimento da identidade da Ciência do Esporte e sua consequente valorização nos (e pelos) programas de pós-graduação em Educação Física e Esporte, esses dados devem ser observados com cautela. É possível que um levantamento mais rigoroso, assumindo a delimitaçáo dos estudos a partir da temática inerente à contribuição do conteúdo e forma de construção da preparação do atleta, e, portanto, refletindo a essência do Esporte, suas condiçóes e caminhos de aperfeiçoamento, implique em uma considerável reduçáo da produçáo real em Ciência do Esporte. Apesar da natureza especulativa desse questionamento, sua razoabilidade "per se", revela a necessidade de uma maior reflexão, discussão e direcionamento acerca da área, do seu papel, e de sua pertinência no programa de pós-graduação da EEFE, na comunidade de pesquisadores da área em geral, e em todas as instâncias nas quais diferentes atores estão envolvidos e, por conseguinte, são os responsáveis pelos caminhos de aperfeiçoamento do sistema. para o programa de pó-graduação da EEFE-USP, e para os demais programas da área, assumindo que o programa da EEFE-USP deve ser refletido com um subsistema de um sistema complexo denominado de pós-graduação, o qual contempla outros subsistemas (programas, agências de fomento, periódicos nacionais e internacionais, etc), os quais, por sua vez, tem suas configurações emergentes determinadas pela interação dos elementos constituintes e as respectivas restrições impostas por diferentes "fontes" e condiçôes. Portanto, as discussóes, reflexôes e consideraçóes acerca do programa de pós-graduação da EEFE-USP, devem ser realizadas reconhecendo dada complexidade. A partir desse raciocínio e abordagem, buscou-se neste texto, levantar questôes, propor concepçóes e conceituaçôes para a Ciência do Esporte, e 
contextualizar os possíveis caminhos para o avanço da área e sua consolidação como uma área específica de conhecimento científico.

Corroborando o cenário explorado por Moreira $^{14}$ é razoável admitir que, no momento, ainda há um distanciamento entre as características dos projetos de pesquisa desenvolvidos (e apoiados, fomentados...) e seus respectivos objetos de investigação (e em consequência, de nossa produção científica) com a Ciência do Esporte. Se quisermos modificar o cenário, deveríamos avançar no desenvolvimento e consolidação das pesquisas pertinentes, de fato, à nossa verdadeira área de atuação, acadêmica e profissional, auxiliando assim no processo de legitimação da identidade acadêmica e da própria profissão. Estudos com metodologias e intervençóes que auxiliem a produção do conhecimento e entendimento fundamental, movidos pelas consideraçóes de uso, e, portanto, com forte relevância e influência no campo profissional e na rotina de trabalho dos profissionais do Esporte devem ser fomentados, estimulados, e desenvolvidos, sobretudo, na esfera da Universidade, e em particular, no seio de nossa pós-graduação, local principal da produção de conhecimento em nossa área.

\section{Notas}

a. O prêmio concedido em 1922 foi dividido igualmente entre este pesquisador, por seu trabalho sobre a produção de calor pelo músculo e por Otto Fritz Meyerhof pela descoberta do relacionamento entre o consumo de oxigênio e o metabolismo do ácido lático no músculo. Contudo, aqui fazemos referência aos trabalhos de Archibald Vivian Hill sobre o consumo máximo de oxigênio.

b. A produção analisada contempla todas as unidades da Universidade de São Paulo, dado que não é possível isolar a produção por unidades. Contudo, supóe-se que a maior produção nesta área advenha da Escola de Educação Física e Esporte e, especialmente, dos docentes vinculados ao programa de pós-graduação.

c. Apesar da área ser identificada como Educaçáo Física nas classificaçóes nacionais, muitos programas vinculados a esta área também conduzem estudos sobre Esporte.

\section{Referências}

1. Cashmore E. Making sense of sports. New York: Routledge; 2010.

2. Tani G. Cinesiologia, educação física e esporte: ordem emanente do caos na estrutura acadêmica. Motus Corporis. 1996;3:9-50.

3. Tani G. 20 anos de ciências do esporte: um transatlântico sem rumo? Rev Bras Ciênc Esporte. 1998; N esp:19-31.

4. Tani G. Área de conhecimento e intervençáo profissional. In: Corrêa UC, organizador. Pesquisa em comportamento motor: a intervenção profissional em perspectiva. São Paulo: Escola de Educação Física e Esporte da Universidade de São Paulo; 2008. p.14-25.

5. Bracht V. Educação física \& ciência: cenas de um casamento (in)feliz. Ijuí: UNIJUÍ; 1999.

6. Matveev LP. Teoría general del entrenamiento deportivo. Barcelona: Paidotribo; 2001.

7. Platonov, VN. Tratado geral de treinamento desportivo. São Paulo: Phorte; 2007.

8. Viveiros L, Moreira A, Bishop D, Aoki MS. Ciência do esporte no Brasil: reflexóes sobre o desenvolvimento das pesquisas, o cenário atual e as perspectivas futuras. Rev Bras Educ Fis Esporte. 2015;29:163-75.

9. Bishop D. An applied research model for the sport sciences. Sports Med. 2008;38:253-63.

10. Bishop D, Burnett A, Farrow D. Sports-science roundtable: does sports-science research influence practice. Int J Sports Physiol Perform. 2006;1:161-8.

11. Stroke DE. O quadrante de Pasteur: a ciência básica e a inovação tecnológica. Campinas: Unicamp; 2005.

12. Rees T, Hardy L, Güllich A, et al. The Great British Medalists Project: a review of current knowledge on the development of the world's best sporting talent. Sports Med. 2016;46:1041-58.

13. Tsigilis N, Grouios G, Tsorbatzoudis H, Koidou I. Impact factors of the sport sciences journals: current trends, relative positions, and temporal stabilitiy. Eur J Sport Sci. 2010;10:81-90. 
Moreira A \& Franchini E.

14. Moreira A. Os maiores eventos esportivos do planeta no Brasil e a pesquisa em educação física e esporte. Rev Bras Educ Fis Esporte. 2014;28:195. Escola de Educação Física e Esporte - USP Av. Prof. Mello Moraes, 65 05508-030 - São Paulo - SP - BRASIL e-mail: alemoreira@usp.br

138 • Rev Bras Educ Fís Esporte, (São Paulo). 2017 Ago; 31(N esp):129-38. 